\title{
Geotechnical value quantification through real options
}

\author{
J Venter AngloGold Ashanti Australia Ltd, Australia \\ ECF Hamman AngloGold Ashanti Australia Ltd, Australia
}

\begin{abstract}
Slope stability acceptance criteria is often applied from standard tables representing industry practice or corporate risk tolerance. While in many cases such standard off-the-shelf solutions are fit for purpose, in the case of slopes with a high value increase per incremental slope angle increase, or where high-cost infrastructure or other sensitive locations are nearby, it pays to have a custom Probability of Failure acceptance criteria determined through risk analysis. The value lies in being able to quantify the consequences of hazards that are slope angle driven, and in determining the mining schedule consequences of these hazards through Probability of Failure.

This paper demonstrates the concept of the risk-based geotechnical assessment through a practical example of a small saprolite pit in West Africa, how such an analysis was carried out, and how the cost-appropriate risk controls were put in place. The example is based on a gold mine, and considers the timing and size of potential failure as well as the mining schedule and cash flow schedule. The type and size of appropriate risk controls are also estimated in the calculation. Finally, the paper demonstrates through the model how the value of geotechnical engineering controls can be calculated using the concept of real options.
\end{abstract}

Keywords: real option, economic risk, cash flow, slope stability

\section{Introduction}

Geotechnical engineering for open pit mining often relies on previously published slope stability acceptance criteria for design decision-making, such as those summarised in the Large Open Pit Project's 'Guidelines for Open Pit Slope Design' (Wesseloo \& Read 2009). Acceptance criteria is often provided in terms of Factor of Safety, but occasionally it is provided in terms of Probability of Failure. The limitations associated with using Factor of Safety have often been discussed by Terbrugge et al. (2006), Steffen et al. (2008) and many others, too numerous to mention and will not be discussed here. Acceptance of economic risk for a given project is influenced by many factors, such as:

- Utilising a risk-benefit approach to realise opportunities.

- The intended portfolio position of a given open pit in the corporate investment stable.

- The optimum risk-adjusted profitability as measured by, for example, the present value of the risk-adjusted mining contribution.

- The presentation of geotechnical risk factors during mining such as a daylighting fault, or undercut critical infrastructure.

- A company's ability to manage the safety risk for a given scenario.

The above factors are not an exhaustive list but serve as a starting point.

In terms of safety risk, slopes are often mined safely right up to collapse using modern monitoring techniques. This illustrates that the technology and economic justification exists to mine slopes safely even if the Probability of Failure is $100 \%$. A model that can be used to predict geotechnical safety risk for open pits was presented by Venter and Hamman (2018a) demonstrating this conclusion practically. Consequently, using 
Probability of Failure alone as an acceptance criteria is an improvement over using Factor of Safety but still leaves room for improvement.

Previous authors such as Contreras et al. (2006), Terbrugge et al. (2006), Steffen et al. (2008), Wesseloo and Read (2009), Contreras and Tunono (2011), Contreras and Steffen (2012), and Contreras (2015) have all proposed, or presented examples of, economic risk models that aim to link Probability of Failure as a geotechnical output, to corporate risk, through mine planning parameters. This paper is based on the model presented by Venter and Hamman (2018b) linking geotechnical risk to a cash flow schedule for a given mining scenario. This model was chosen because it has the added advantage of being capable of calculating the cash flow of the main geotechnical choices in terms of risk management:

- Proactive design verification through data collection and analysis.

- Reactive slope instability detection through monitoring.

- Managing instability after it occurs.

As will be explained in the next section, these choices are equivalent to options that have to be purchased by paying for the work needed before a given choice can be made. If the work was not carried out in time, a particular choice is not available if slope instability occurs.

This paper applies the model proposed by Venter and Hamman (2018b) to a small saprolite pit in West Africa to calculate the value of the geotechnical work for that pit.

\section{Real options}

\subsection{Simplified theoretical background}

An easily understood treatise on real options from an engineering point of view is provided by Crundwell (2008) and more elaborate treatises are available such as Hull (2003). As a result, only a short introduction will be given here.

Call options are financial instruments traded on the stock market that give the purchaser the right, but not the obligation, to purchase a given share (the underlying security) on a given date (the exercise date) for a predetermined price (the strike price). For instance, purchasing a call option today based on XYZ Mining Company shares with a strike price of USD 10 on 12 April next year gives the option purchaser the right, but not the obligation, to purchase one XYZ Mining Company share for the price of USD 10 on receipt of the option certificate on 12 April next year. Having this information leaves the prospective option purchaser with two questions:

- What is their view of the underlying security share price on the exercise date?

- How much should they pay for the option today?

For financial securities, answering these questions represents entire fields of study and are not answered here. Options are usually sold by banks or other trading institutions but not by the underlying securities and are one of the many market instruments used for hedging (i.e. risk management). There are also other types of options and other variations on strike price and exercise dates but the reader is referred to texts such as Hull (2003) for more detail.

Real options are real-world scenarios that are mathematically similar to options (call options or put options depending on the case) in that money changes hands today for some advantage in the future. For instance, a person may pay a holding deposit to a property developer today for the right to purchase a given property by a given date in the future for a fixed price. Should the would-be purchaser decide not to proceed, the holding deposit is forfeit, making the holding deposit equivalent to an option purchase. 


\subsection{Proposed application}

The view of open pit geotechnical engineering in this paper is that from an economic point of view, geotechnical engineering is equivalent to purchasing an option to protect against economic slope instability risk. To be more specific, there are three possible choices to be made when dealing with slope instability as presented by Venter and Hamman (2018b). These are:

1. Option 1: eliminate potential instabilities by changing the slope profile before mining progresses to the point where these instabilities are activated. This risk management option is only available if the activities associated with proactively detecting potential slope instabilities, before they initiate, are carried out (and hence the option purchased). These activities include, among others, in-pit mapping, structural geology analysis, laboratory testing and additional core drilling to validate/invalidate the pit design assumptions. The value of removing potential instabilities before activation is that one has more time to produce remedial actions (latency) as well as limiting the cost of remedial actions as slopes will not be as high as when remediation occurs. Of the three choices, removing instabilities before they activate is potentially the cheapest, but is only available if the option is 'purchased' by funding the necessary activities.

2. Option 2: limit the damage caused by activated instabilities through unscheduled cut-backs, buttressing or delays to let the slope velocity regress. This risk management option is only available if the activities associated with reactively detecting slope instability initiation, using geotechnical monitoring, is carried out. Limiting damage is associated with higher slopes, hence more remediation volumes, and more damage already done, resulting in limited remedial options and less time in which to remediate (less latency).

3. Default outcome: allowing slope instability to occur, followed by clean-up and re-establishment of access. Allowing a slope instability to occur is associated with no latency, few remediation options and significant remediation cost. Allowing slope instability to occur is often the most expensive of the options and is always available. This is the default outcome if the other options are not 'purchased' by engaging in the associated activities.

In summary, the first two options, eliminating and limiting damage, are only available if the associated options are 'purchased' by funding the correct activities. The last option, allowing slope instability to occur, is the default position if no other actions are taken. Lastly, just because a particular option is available does not mean it has to be exercised. For example, should a particular slope instability mechanism be detected proactively but the cost estimate for letting the slope collapse is the cheapest compared to slope remediation. There is no obligation to remediate the slope. It can simply be allowed to collapse, provided the safety risk is under control.

This paper proposes that the value of proactive and reactive geotechnical activities can be determined by calculating the difference between the risk-adjusted net present value (NPV) assuming slope instability occurs, and the risk-adjusted NPV assuming that proactive or reactive geotechnical activities take place (i.e. calculate the value add of these activities compared to the 'do nothing' scenario). This valuation is carried out singly for proactive and reactive activities respectively, but also the combined valuation. Such a calculation will allow mine management to decide on the relative importance of these activities on a pit-by-pit basis. The proposed model is presented in the next section, followed by the example.

\section{$3 \quad$ Proposed model}

The model used in this paper is the same as that presented by Venter and Hamman (2018b). However, since the original publication some changes were made to the outputs based on experience. The slope instability timeline and decision tree as presented by Venter and Hamman (2018b) are unchanged and again repeated as Figures 1 and 2, respectively. Figure 1 starts by showing a contextual model representing the four life stages of a geotechnical hazard as design, validation, creep and, finally, collapse. Figure 2 shows the decision tree that forms the basis for the options valued in this paper. 


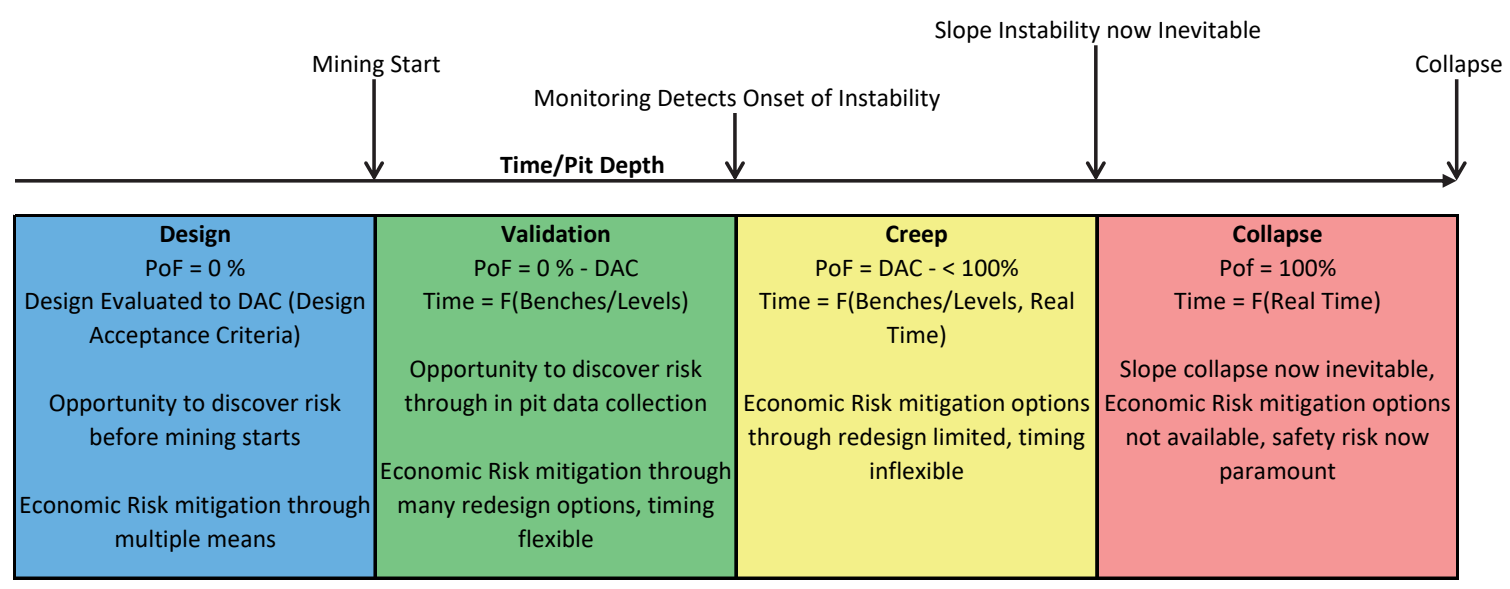

\section{Figure 1 Proposed risk model}

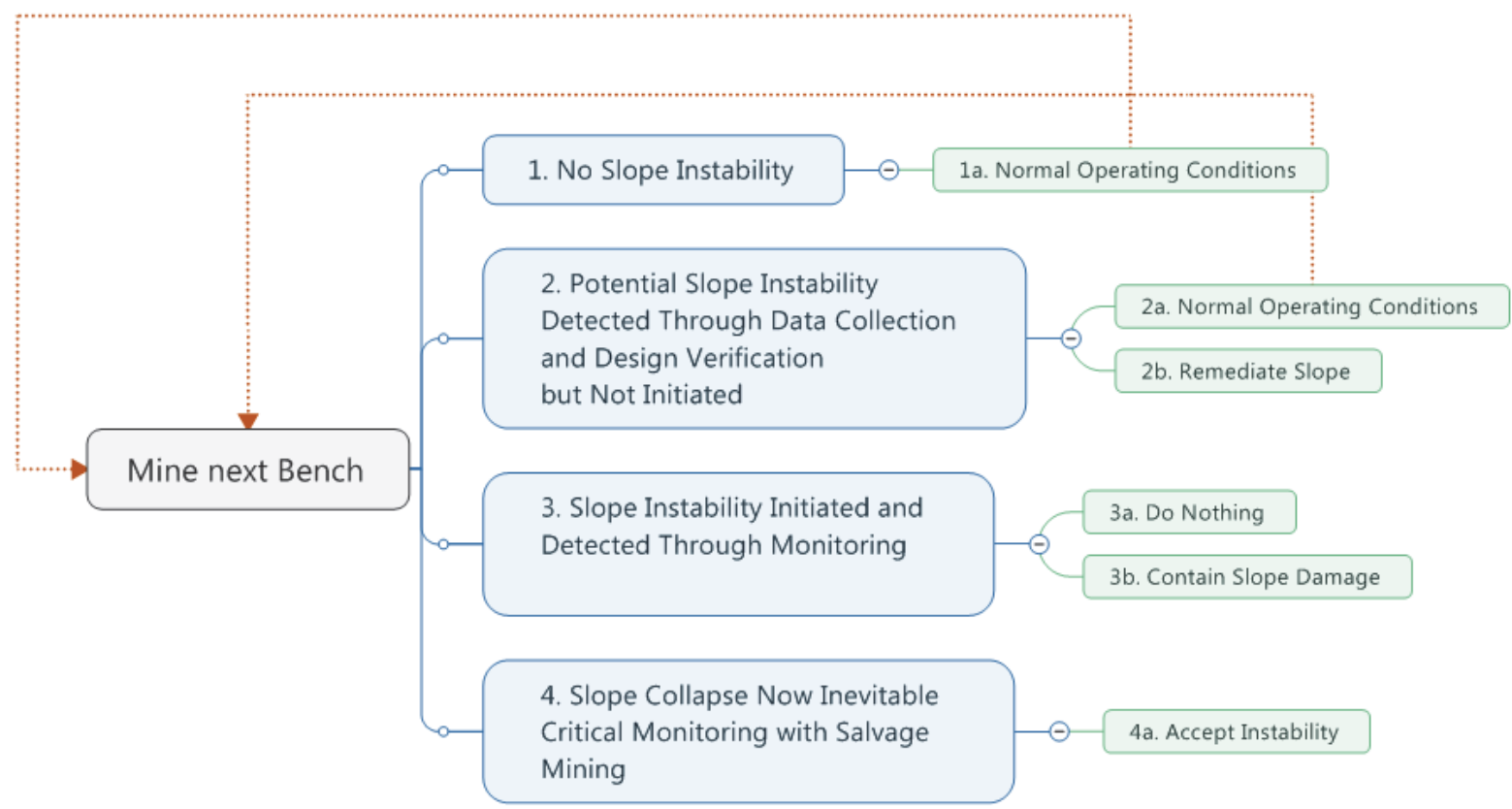

Figure 2 Economic risk decision tree

In summary, the four stages of a geotechnical hazard as presented in Figure 1 are:

1. Design: The design stage represents the time period before mining commences. The actual open pit risk during this period is zero (even though a report may exist presenting a Probability of Failure) as there is no excavation yet. If this design is for a cutback, any risk associated with the excavation still belongs to the previous design and not the cutback design. The major features of the design period are that:

a. There are practically no limitations imposed on potential design except those imposed by the project owner.

b. The information available for a design is often limited to boreholes and surface mapping, as no excavation may be present. Even if existing pits are nearby, such as during a cutback, details of the structural variations at the exact location of the slopes are likely to be incomplete.

2. Validation: The validation stage represents a period of time following the blasting of the first bench during which prisms and other long term trend monitoring tools can be installed, and measurement histories started. Early information from in-pit mapping and mining experience can be used to validate the design and identify previously unknown hazards. As this period ends for a slope once 
the first significant instability is initiated, it represents a golden period of proactively detecting potential instabilities with sufficient time to change pit designs while maintaining schedule flexibility. The main purpose of slope monitoring in this stage should be to detect the onset of the creep stage.

3. Creep: The creep stage represents the period of time after initiation of a significant slope instability but before it is too late to prevent the instability through slope design changes or remediation measures. The exact start of the creep stage may not be precisely pinned down, due to the lack of information or imprecise equipment. The exact end of the creep stage is as much a function of the mine's ability and willingness to intervene as it is of the slope's mechanical disposition to collapse. For example, the life of the creep stage can consequently be shortened by deciding not to build the buttress even if it technically would have worked. The end of the creep stage represents the end of all opportunities to limit economic damage by changing the slope geometry. The purpose of slope monitoring during the creep stage is to detect the onset of the collapse stage, and to provide inputs for the safety risk model presented in this paper.

4. Collapse: The collapse stage represents the final stage before collapse and is entered into the moment slope collapse becomes inevitable. At this point, economic damage becomes inevitable and is locked in; the only control remaining is to continue mining as long as mine management is comfortable with the level of safety risk, based on the quality of real-time monitoring available.

In short, the basic theme behind the stages are that the closer a slope gets to collapse in terms of slope height, the less latency one has, and the more volume of waste will need to be moved to remediate a slope or limit the damage. The likely volume of ore loss will also increase as failure volume increases with slope height.

This paper focuses on the first three of these stages, which deal with design changes. The fourth stage, which covers safety monitoring, is covered in Venter and Hamman (2019).

\subsection{Introduction to the risk model}

The model is based on a simple yet realistic decision tree presented as Figure 2 . Unlike other models used however, this tree is evaluated each time a new time step is mined. In the case of the example presented in this paper, time steps are in weeks. Four possible outcomes are recognised each time a new time step is completed:

1. No slope instability: This outcome is what is expected most of the time and is followed by a decision to continue mining under 'normal operating conditions'.

2. Potential slope instability detected: This outcome occurs when the geotechnical team, through ongoing data collection and design assumption validation analysis, detects a previously unknown geotechnical hazard that could lead to slope collapse if the slope design is not amended. This is a future scenario and implies that the failure mechanism driving this hazard has not yet been activated. Naturally, this scenario can only occur if the site geotechnical team is correctly resourced and empowered to carry out such analysis (i.e. option 1: eliminating potential slope instabilities is purchased). This scenario also represents the second line of defence against geotechnical risk (the first line being geotechnical design before start of mining).

3. Slope instability initiated and detected through monitoring: This outcome occurs when the geotechnical team, through slope monitoring activities such as prism monitoring, inspections, time domain reflectometers, etc., detect that a slope has started responding to mining through plastic deformation of sufficient magnitude to be detected. Slope collapse is still not certain but the Probability of Failure of the slope can now be assumed to be greater than that obtained during design calculations (assuming damage scenarios were not assessed during the initial design), but still less than $100 \%$. As for the previous scenario, this scenario can only be achieved if the relevant monitoring activities are resourced (i.e. option 2: limiting slope damage is purchased). This scenario 
represents the third line of defence against geotechnical risk. It is at this point that additional activities are often considered:

a. Additional monitoring equipment such as slope radars and associated trigger action response plans (TARPS).

b. Slope remediation that may stop or delay slope instability such as unloading the crest or buttressing the toe, etc.

4. Slope collapse now inevitable: This outcome occurs when the point is reached where no amount of slope remediation can prevent slope instability and is the default outcome if neither option 1 nor option 2 is purchased (i.e. no data collection with design verification and no monitoring). There are only two questions to answer:

a. When does the pit need to be evacuated?

b. How much ore can be extracted safely before that happens?

This stage is characterised by critical monitoring. This represents the fourth and last line of defence against slope instability.

In summary, there are four lines of defence against geotechnical risk:

1. Initial pre-mining geotechnical design.

2. Purchase option 1 by carrying out ongoing data collection and design validation analysis.

3. Purchase option 2 by carrying out low monitoring frequency and high precision, but ubiquitous coverage pit slope monitoring.

4. Accept slope collapse and carry out critical monitoring characterised by high to continuous monitoring frequency, ultra-high precision, spatially targeted pit slope monitoring with alarms and associated additional controls.

The economic risk model recognises each of these stages and also provides as output the likelihood of being able to manage geotechnical risk at each stage for every mining step, based on the geometry of the open pit and the resourcing of the geotechnical team. It is this component of the economic risk model that allows it to be used for geotechnical workflow planning based on corporate risk acceptance.

\subsection{Risk model inputs}

The economic risk model requires, as inputs, the following information for each bench/mining step mined (all node references with respect to the decision tree in Figure 2):

- Physical mining assumptions:

- The number of possible dig faces for use in determining remaining production in case of slope instability.

- The number of accesses to the pit for use in determining remaining production in case of slope instability.

- The number of shovels. Again, for estimation of production should a shovel be affected by slope instability.

- Mining schedule and cost assumptions:

- Schedule time for completion of each mining step. As the regularised time step for the model is mining weeks (or alternatively a mining step if more complicated mine geometries are used), the link to real time is needed for time value of money calculations. The model uses an end of period convention for time value of money calculations. 
- Ore mining cost per tonne. For use in estimating slope remediating costs. Grade is rarely binary and many mines have different types of grade such as full-grade ore and marginal ore for precious metals or high-grade ore and low-grade ore for iron ore. This model assumes a binary distinction although the actual ounces or tonnes of ore is used in the calculation. This means that all ore, regardless of grade, contributes to revenue. If some ore categories are stockpiled, these need to be treated as waste in this model.

- Waste mining cost per tonne. For use in estimating slope remediating costs.

- Pit geometry assumptions:

- Elevation (or other reference value) for easy reference.

- Bench height.

- Waste tonnes per mining step.

- Ore tonnes per mining step.

- Ounces per mining step for revenue estimation (can be replaced by other measures for different commodities).

- Slope instability management assumptions:

- Number of shovels dedicated to slope remediation or failure clean-up.

- Broken rock mining cost per tonne.

- Broken rock mining rate per shovel per month.

- Intact rock mining rate per shovel per month.

- Estimation of ratio between broken and intact rock for clean-up cost estimation.

- Geotechnical design Inputs:

- Probability of Failure per slope sector per mining step. These are needed for risk-adjusted mining contribution calculations and refer to slope instabilities of sufficient scale to affect production either in terms of delays, or in terms of clean-up or remediation volume.

- Estimated tonnes per instability for each slope sector for each bench.

- Economic risk decision tree (Figure 2): node 1 - as node 1 represents normal operating conditions, no additional information is required.

- Node 2 - detection of potential instability before initiation:

- Percentage data availability to proactively detect slope instability.

- Percentage data gathered to proactively detect slope instability.

- Percentage data analysed to proactively detect slope instability.

- Node $2 \mathrm{~b}$ - estimate of potential ore loss to prevent instability.

- Node $2 b$-estimate of potential waste mining to prevent instability.

- Node 3-Detection of initiation of real instability through slope monitoring:

- Estimate of potential ore loss to prevent instability.

- Estimate of potential waste mining to prevent instability.

- Estimated duration from initiation to collapse in benches/mining stages.

○ Node $3 b$ - percentage of slopes covered by monitoring sensors (i.e. prisms). 
- Node $3 b$ - percentage of sensors read frequently and correctly.

- Node $3 b$ - percentage of sensors precise enough to detect instability.

- Node $3 b$ - percentage of sensors analysed correctly to detect instability.

- Node 4-recovering from slope collapse:

- Mining to re-establish access in tonnes.

- Ore loss following instability in ounces. Again, other units can be used where appropriate.

- Cost associated with loss of critical infrastructure such as public roads, crushers, heritage sites, etc.

- Financing information:

- Inflation rate.

- Investment hurdle rate.

- Gold price assumption (or alternate commodity prices).

These inputs, provide sufficient information to analyse an open pit scenario in full according to the model.

\subsection{Risk model outputs}

Naturally, a model such as this provides, as outputs, a database that can be interrogated for a significant amount of information. However, after some practical use since Venter and Hamman (2018b), the main outputs of the model may be summarised as follows: expected revenue and risk-adjusted revenue

- Graph of Probability of Failure for each mining step. The risk-adjusted revenue assumes that attempts are made to manage slope risk using each of the four geotechnical risk management stages according to the abilities of the geotechnical effort applied for the pit. The model calculates the likelihood of each stage being successful based on the information provided. The risk-adjusted revenue can be compared with the expected revenue, which ignores geotechnical risk.

- Graph of expected slope failure volume, potential waste savings volume and Probability of Failure versus mining step. The expected failure volume gives an indication of the likely size of large instabilities should they occur. The potential waste-savings volume is based on the information provided for a potential upside pit shell scenario and shows the value gained should this upside pit shell be selected at a given mining step.

- Graph of the likelihood of each stage of geotechnical risk management being successful versus bench/stage mined, based on the slope-management information provided. This graph reflects past performance and quantifies its effect on the pit economics. It also provides an opportunity to quantify what changes are needed to improve risk management. Finally, this graph may also provide some information to help decide whether any of the geotechnical risk management stages should be deliberately abandoned, as it does not provide any benefit for a given open pit. An example of this may be small pits mined quickly where the second stage, proactive data gathering, may not be practical due to the short pit life. In essence, this graph provides a measurement of how much the pit shell risk was hedged through purchasing of options 1 and 2.

The financial outputs that follow are based on the mining contribution which is calculated as:

Mining contribution $=$ revenue - mining cost - slope remediation cost

- Present value mining contribution versus bench/stage mined, for each of the four geotechnical risk management stages. The mining contribution is used in this model as it allows mining costs to be separated from processing costs which are not needed for slope angle purposes. The mining contribution graph can be read as 'what if' scenarios. 
What if slope instability occurred in a given week?

$\circ$ What if the potential upside pit shell was selected?

- What would the net mining contribution be going forward for the aforementioned 'what if' scenarios?

- PV(cumulative mining contribution) versus mining step, for each of the four geotechnical risk management stages. The Cumulative Mining Contribution is taken up to and including the mining step (i.e. from mining step 1 to mining step 4 for mining step 4). This indicator presents a useful comparison as it highlights the value contribution of mining one more mining step. In many cases, it may be more profitable to steepen the slopes and give up the last benches than to mine to a given depth. This may be due to low ore contribution (in which case mine planning software is expected to drive this conclusion) or high additional geotechnical risk accumulation. In the latter case, mine-planning software will be oblivious to the additional risk and in such cases will drive too flat slopes mined too high.

- $\mathrm{PV}$ (cumulative mining contribution) improvement or erosion. As the previous indicator (cumulative mining contribution) sums all the values over the life of the pit; the differences between lines on the graph are not always clearly visible. This graph presents the same information as the previous indicator but normalised with respect to the base case expected mining contribution.

- Instability clean-up time in weeks due to slope instability. This indicator is very useful as many mines can manage geotechnical instability by keeping stockpiles. This value is used to determine stockpile size at various benches/stages. The information to provide a stockpile size versus confidence graphs is also available in the model.

\section{$4 \quad$ Example open pit, West Africa}

The pit selected as the case study for this paper is a saprolite pit in West Africa. The example pit was selected for two main reasons.

Firstly, it represents a small saprolite pit and is representative of many smaller soft rock pits all over the world. The results could therefore be extrapolated with some confidence to other locations.

Secondly, the pit was mined out in a short period of time of about three months and was stopped $5 \mathrm{~m}$ short of the design floor due to water-related slope instability. It therefore presents a neat closed system case study where hindsight could be used to test decisions that would have been made if the model was applied beforehand. The steepest section of the pit slope is presented as Figure 3, a drone photo and actual pit triangulation is presented as Figure 4, and a photo of the instability encountered as Figure 5.

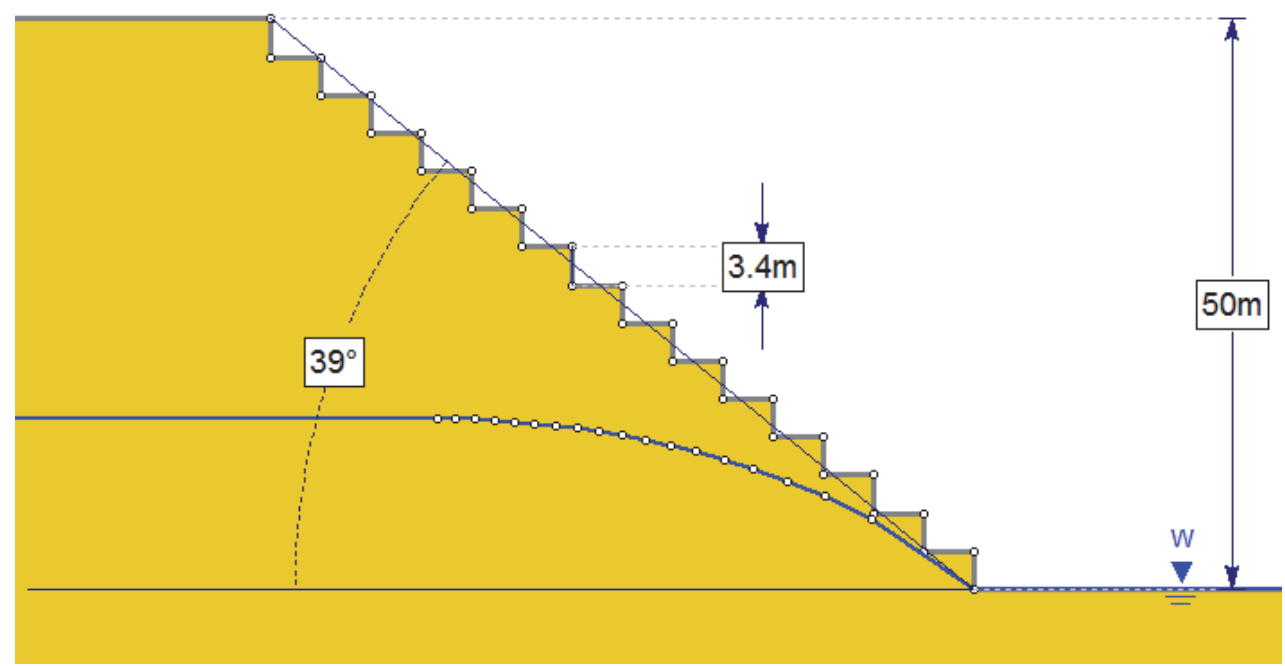

Figure 3 Maximum height slope section - example open pit 


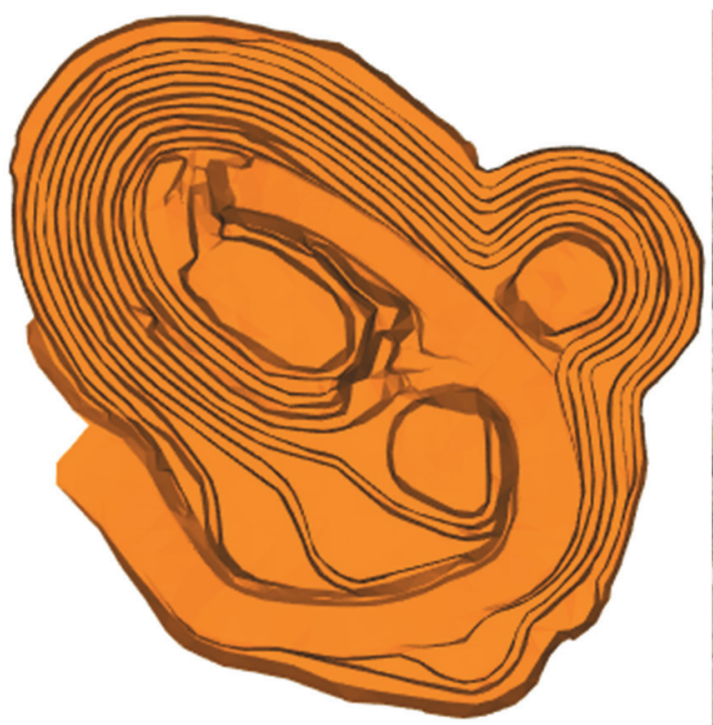

(a)

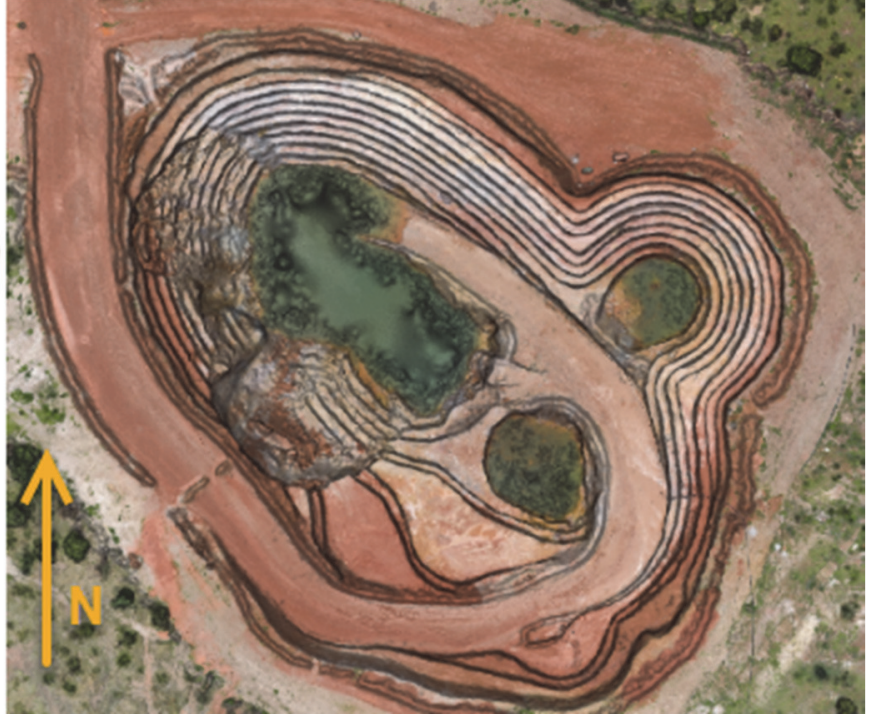

(b)

Figure 4 (a) Example actual triangulation; (b) Drone photo

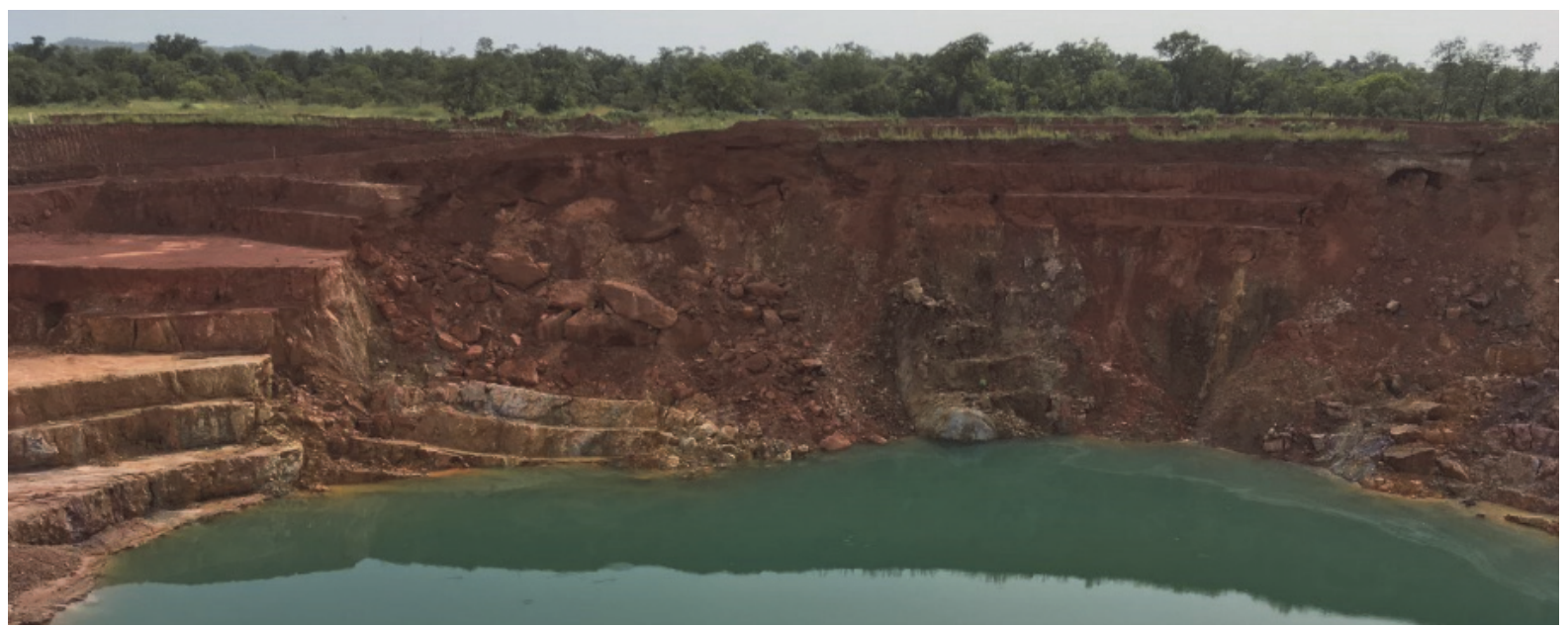

Figure 5 Slope instability photo

\subsection{Model inputs}

The main model (Figure 3) inputs of importance for the example are:

- A $50 \mathrm{~m}$ high slope at $39^{\circ}$ with a water table $15 \mathrm{~m}$ above the pit floor.

- There is no public infrastructure near the pit.

- All the inputs for the economic risk model were based on measured tonnes, resource model grades and a gold price assumption of USD 1,200/oz.

- The Probability of Failure was calculated based on a number of back-analyses of slope instabilities that occurred in saprolite slopes at the mine site.

- The slope had a life of three months and the model timescale is based on weeks.

- It has been assumed that at a mining depth of $40 \mathrm{~m}$, sufficient information is available to verify the design assumptions. This may appear extreme; however, given the small benches ( $3.3 \mathrm{~m}$ high), the only opportunity for back-analysis is when the slope approaches its full height.

- As no data was collected for this pit, this is reflected in the assessment. 
- An upside scenario was evaluated, which increased the overall slope angle from $39^{\circ}$ to $42^{\circ}$. The Probabilities of Failure were calculated for each mining step using the same material parameters as for the base case. The volumes of waste reduced for the potential upside was evaluated using Figure 6. Figure 6 presents the volume reduction from base case versus slope angle increase from base case. For example, when starting with a $40^{\circ}$ base case, increasing the slope angle by $2^{\circ}$ to $42^{\circ}$ will decrease the volume of waste mined above the slope by approximately $7 \%$. A $10 \%$ reduction in waste was applied in this example.

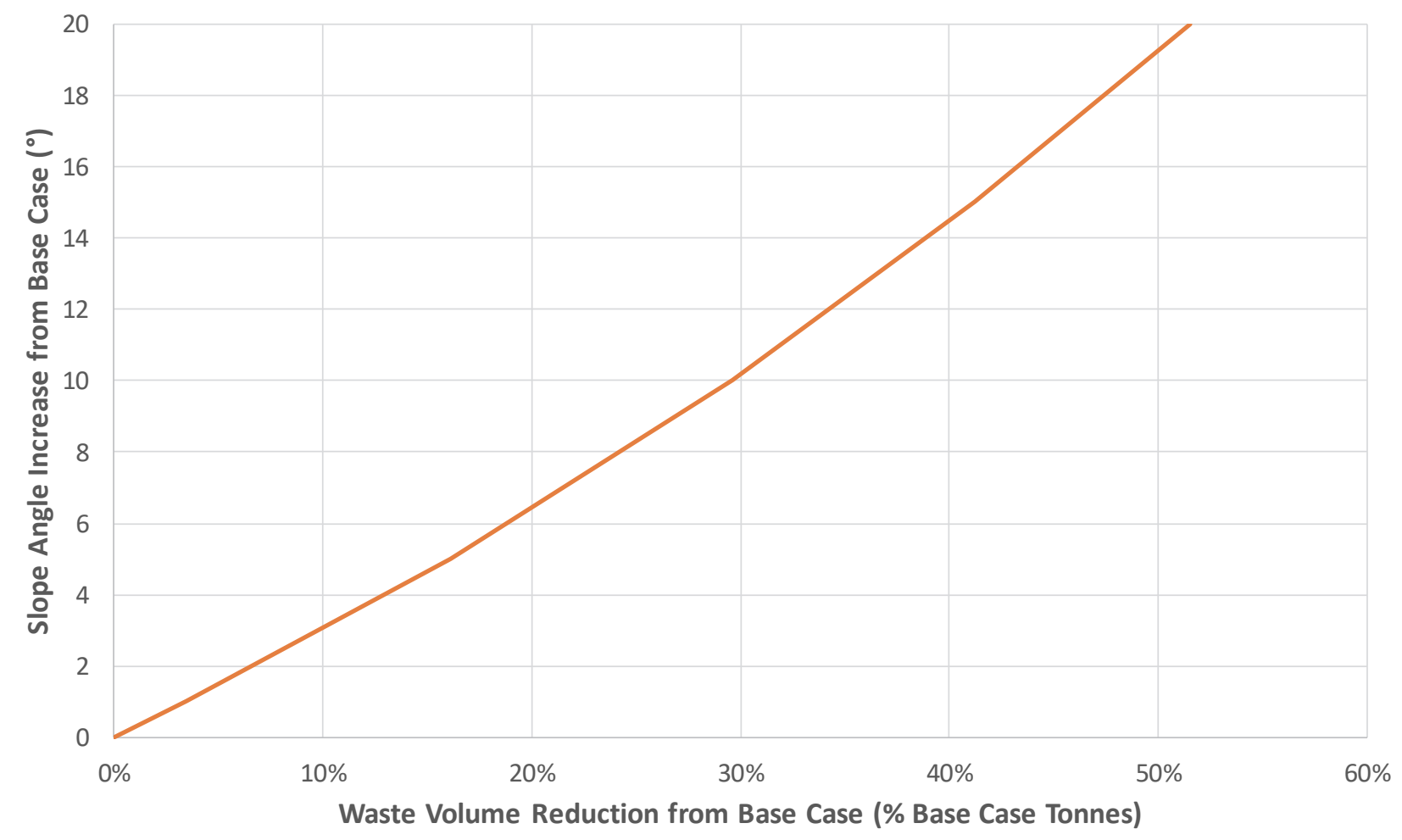

- 40 deg Base Case

Figure 6 Waste volume reduction versus slope angle improvement

\subsection{Model results}

The model results are presented as Figures 7 to 12 . The results are discussed one at a time in the following sections.

\subsubsection{Probability of Failure versus revenue}

The first graph (Figure 7) shows the expected revenue (ounces $\times$ gold price) and risk-adjusted revenue where:

Expected revenue $=$ ounces $\times$ gold price

Risk-adjusted revenue $=$ expected revenue $-P($ failure $)] \times P($ proactive slope management $) \times$ (proactive ore loss value) $-\mathrm{P}$ (reactive slope management) $\times$ (reactive ore loss value) $-\mathrm{P}$ (no slope management $) \times($ slope collapse clean-up ore loss value)) .

The risk-adjusted revenue is a measure of the Probability of Failure and the mine's ability to manage geotechnical risk based on their geotechnical decisions in the context of the two risk-management options. Figure 7 also shows the Probability of Failure to be read on the right hand y-axis. 
From Figure 7, it can be seen that up to week 10, the expected revenue and risk-adjusted revenue differs only a little. At week 11, however, the difference is approximately USD 1 million. This is driven by the increase in Probability of Failure caused by the water table.

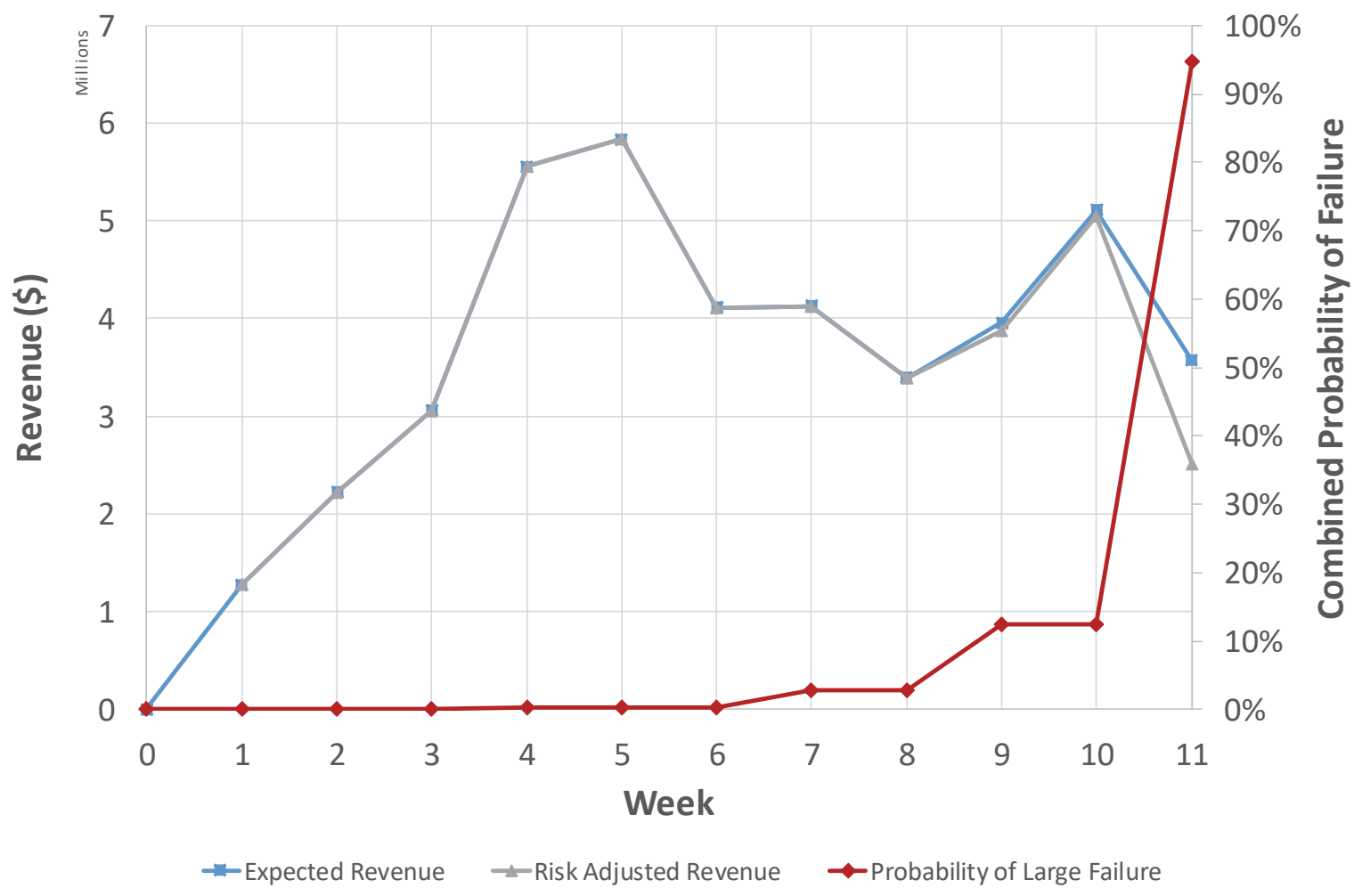

Figure 7 Probability of Failure versus revenue

\subsubsection{Geotechnical risk management confidence}

The third graph (Figure 8 ) shows the probability of managing risk by purchasing geotechnical risk-management options 1 and 2. Figure 8 shows that geotechnical risk management option 1 (proactive risk management) was not purchased, as for such a small pit based on saprolites this activity would not add value. Geotechnical risk-management option 2 was however purchased as geotechnical inspections and slope radar was used in this pit. The slope radar may seem overkill; however, given the short duration of the pit and the fact that a radar was already available, it provided an additional control.

The probability of proactively managing risk is given by:

$\mathrm{P}($ proactive risk-management $)=\mathrm{P}[($ available response time $)-($ required response time $)>0]$ where:

Available response time $=$ (bench completion month) $-\left(1^{\text {st }}\right.$ month of $100 \%$ data available, $100 \%$ data gathered and $100 \%$ data analysed).

Required response time $=$ (remediation mining volume) $/$ (remediation mining rate) . 


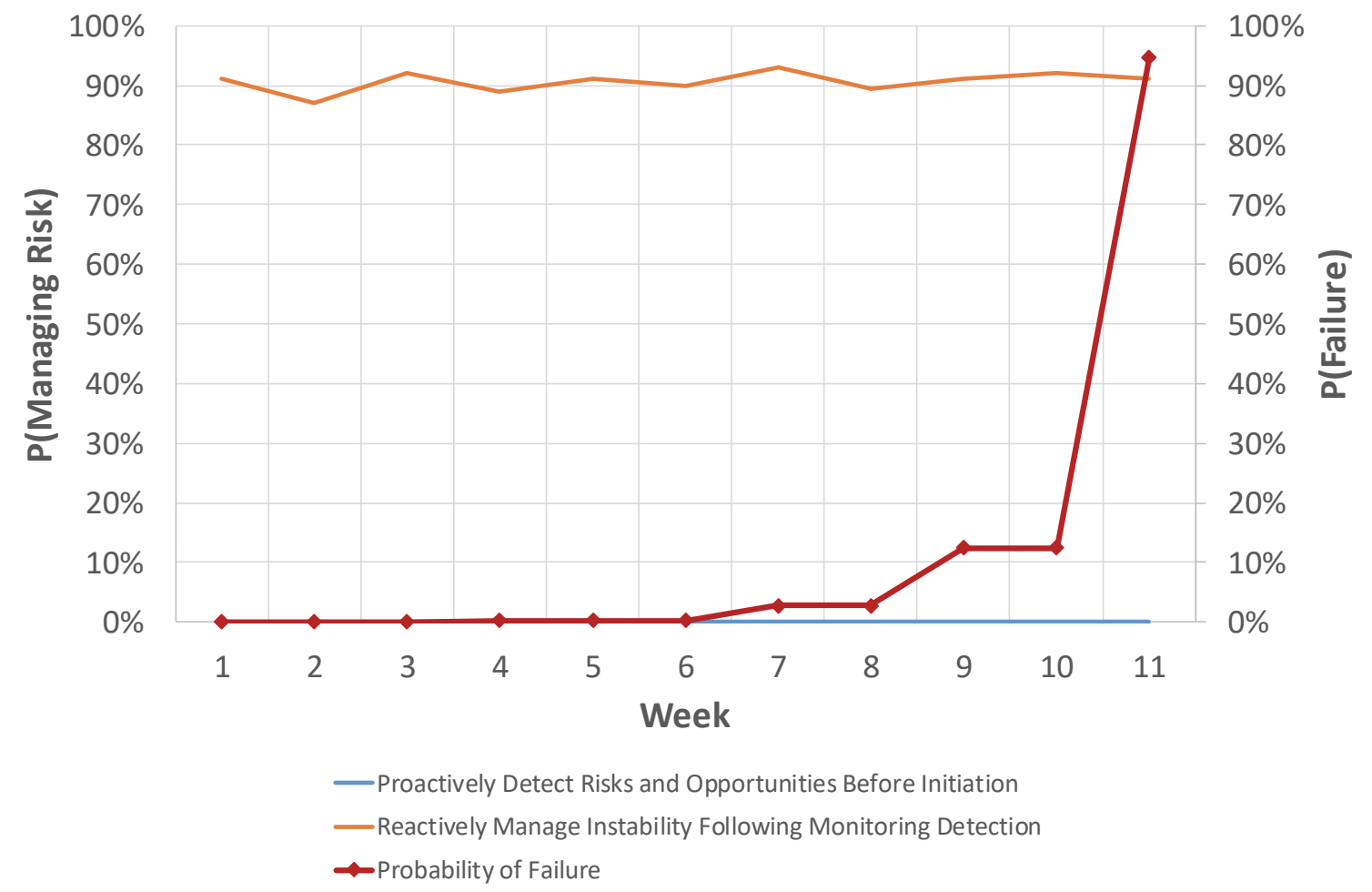

Figure 8 Geotechnical risk management confidence

Proactive risk-management assumes a zero production gap as it is considered unlikely that a mine will decide to stop production to remediate a slope based on a risk that has not yet initiated. The remediation mining rate is a function of the number of shovels that can be dedicated to remediation work. In practice, this could be a dedicated reserve shovel, a rented shovel, or a portion of underutilised time from a production shovel.

The probability of reactively managing risk is given by:

$\mathrm{P}($ reactive risk-management $)=\mathrm{P}[($ time to inevitable failure $)$ (response time to remediate)

- (time wasted due to monitoring delay) $>0$ ]

Time to inevitable failure is provided as input for each slope sector and is based on the monitoring data.

Response time to remediate is based on a volume and mining rate calculation as for proactive management, again assuming a zero production gap.

Time wasted due to monitoring delay is given by:

Time wasted due to monitoring delay $=$ (delay from initiation to detection $)+[1-\mathrm{P}$ (monitoring detects initiation $) \times($ remaining time till end of pit life)]

with:

$\mathrm{P}($ monitoring detects initiation $)=(\%$ slopes covered by sensors $) \times(\%$ sensors being read frequently and to specification) $\times(\%$ sensor data analysed correctly)

From the Probability of Failure line in Figure 8 , it is clear that geotechnical risk tends to be low for the first six benches and only creeps up above $10 \%$ from bench 7 onwards. Inspection of the proactive risk-management line shows zero capacity for the first four benches, climbing to above $90 \%$ capacity after bench 7 . The assumption made in this assessment is that the mine will have to develop for three benches before sufficient information is available to completely validate the structural model. This delay is not caused by management error, as perfect behaviour is assumed, but due to the additional data that can only become available once the open pit excavation extends through the weathered zone and sufficient fresh rock faces are exposed to update the structural model and verify the geotechnical logging through face mapping. The proactive risk-management line therefore presents a best case scenario. 
Notice also the delay from bench 3 (when perfect data becomes available) to bench 6 (when the capacity to manage risk is high). This delay stems from the time needed to remediate the slope before getting to the actual bench at risk. Knowledge available at the end of bench 3 can therefore only be used with significant confidence to prevent production delays from bench 6 onwards. Any slope instabilities that occur between benches 3 and 6 , may be predicted before initiation, but without sufficient time to remediate before experiencing production delays. Strategies for fixing this problem are expensive and contain actions such as:

- Mining successively expanding pit shells with many cuts to allow the rock fabric and structural model to be completed to greater confidence in small exposures.

- Mining long orebodies from one end to the other to allow structural models to be inferred as the pit progresses.

- Spending more money up front to maximise orebody knowledge before mining starts. This includes multiple drilling, data processing, design, gap analysis, and drilling cycles.

All the above strategies are costly and, in high volume cases such as iron ore and coal where pit turnover can be quick, the risk may simply be accepted. The economic risk model presented in this paper does, however, present the mine owner with a tool to make this a conscious and informed decision as opposed to an implied non-communicated decision.

The last line in Figure 8 is the ability to reactively manage risk using geotechnical monitoring. The assumptions made for this demonstration is that of a mine where the geotechnical team carries out their functions perfectly, however, they rely on manually collected and imprecise prism data that will only warn them of failure initiation between $1 / 2$ and $11 / 2$ benches after initiation took place. Again, the loss of monitoring value in this model is economic, and the drop from an expected $100 \%$ value to approximately $50 \%$ is due to the time needed to remediate without incurring a production delay. Incidentally, if the prism monitoring is upgraded to only incur an average delay of 0.2 of a bench (representing, for instance, one mining block out of five on this bench level), the effectiveness increases to almost $100 \%$. This is also linked to the speed at which a failure mechanism activates. As this example is for a saprolitic soil mass, the mechanism activates slowly, but if undercutting of bedding in hard rock was involved, for instance, much less effectiveness would be achieved.

\subsubsection{Present value of mining contribution}

The fourth graph (Figure 9) shows the hypothetical present value of mining contribution versus mining step should slope instability occur and is a measure of the effectiveness of each of the three risk-management strategies (option 1: proactive, option 2: reactive, or option 3: clean-up). This value is calculated as:

Present value mining contribution $=($ ounces $/$ bench $) \times($ gold price $)-($ regular mining cost $)-($ ore loss $) \times$ (gold price) - (remediation mining cost)

for each risk-management option.

This allows the relative importance of each risk-management stage to be measured. The advantage of this method is that future scenarios can be tested, but the effect of past performance can also be accounted for.

Figure 9 shows that for the example pit, purchasing option 1: proactive geotechnical risk management would have been the most effective as it had the highest mining contribution. It would, however, have been difficult to collect design validation information and redesign the pit within the three months it took to mine. The next most valuable option was option 2: reactive risk management, followed by the default option 3 of allowing the instabilities to occur. However, most of the value of the different options is only realised in the last few weeks as the gap between the reserve mining contribution and the option values increase. The advantage here is very small compared to weekly revenues. 


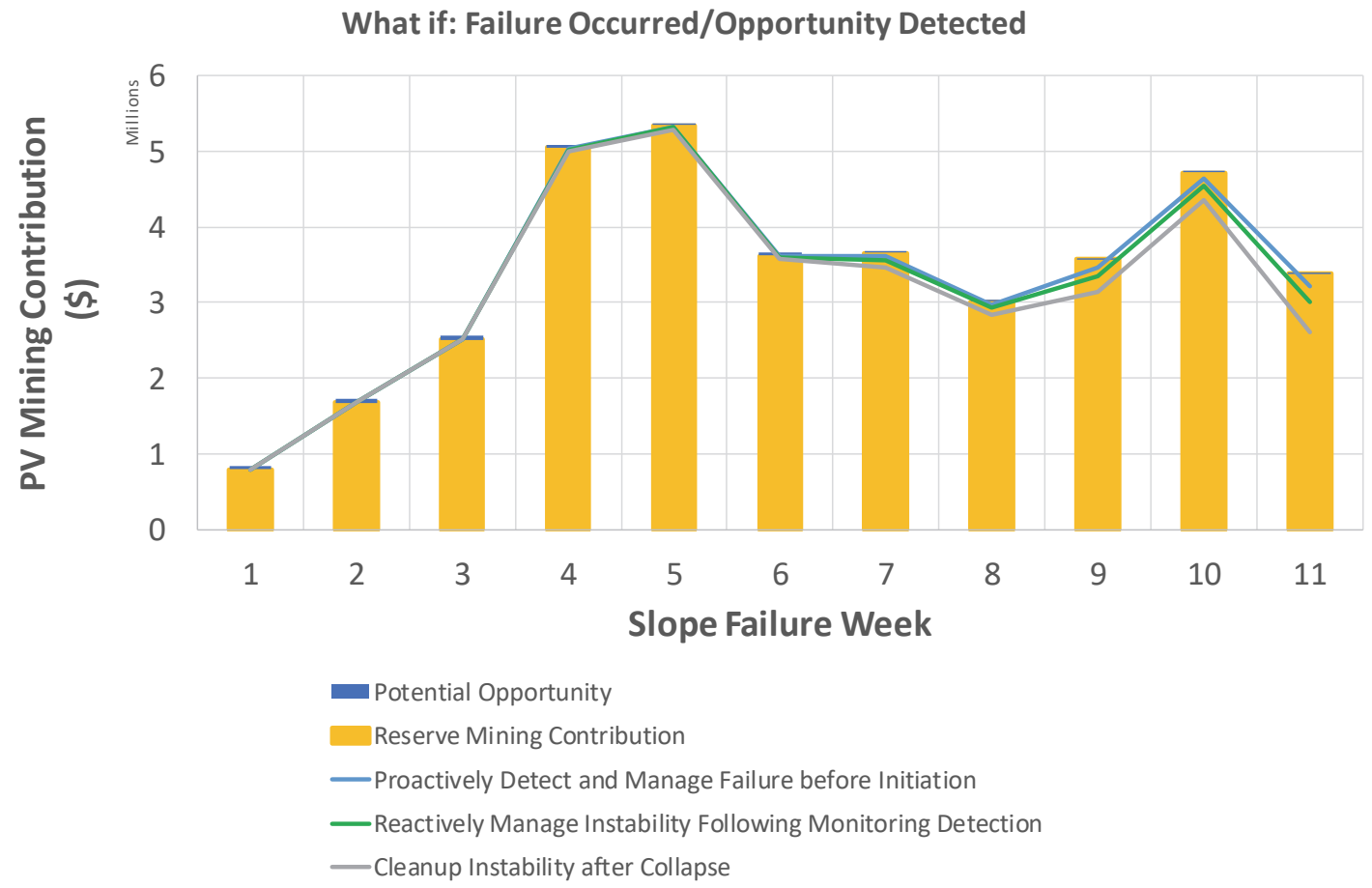

Figure 9 Mining contribution

\subsubsection{Present value of mining contribution}

While Figure 10 shows mining contribution per mining step, Figure 11 shows the present value of the cumulative mining contribution for all mining to a given mining step. This is useful as it allows one to understand the effect of risk over the project life, not just per bench. Figure 11 shows that down to week 10, none of the options would have made a significant percentage difference to the present value of the cumulative mining contribution compared to the overall value of the pit. In week 11 , there is a small increase in value due to better slope management.

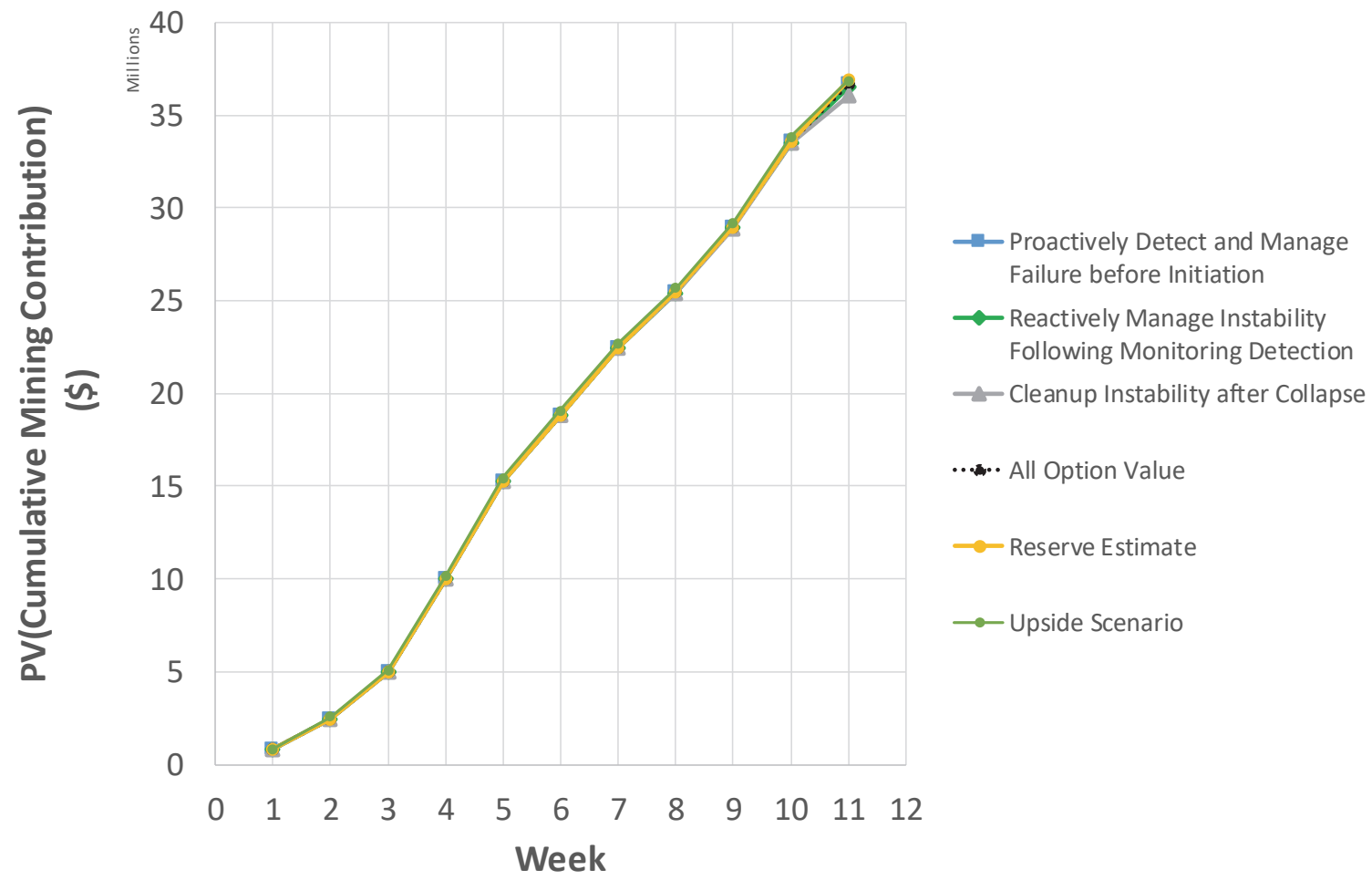

Figure 10 Sum of present values of mining contribution 


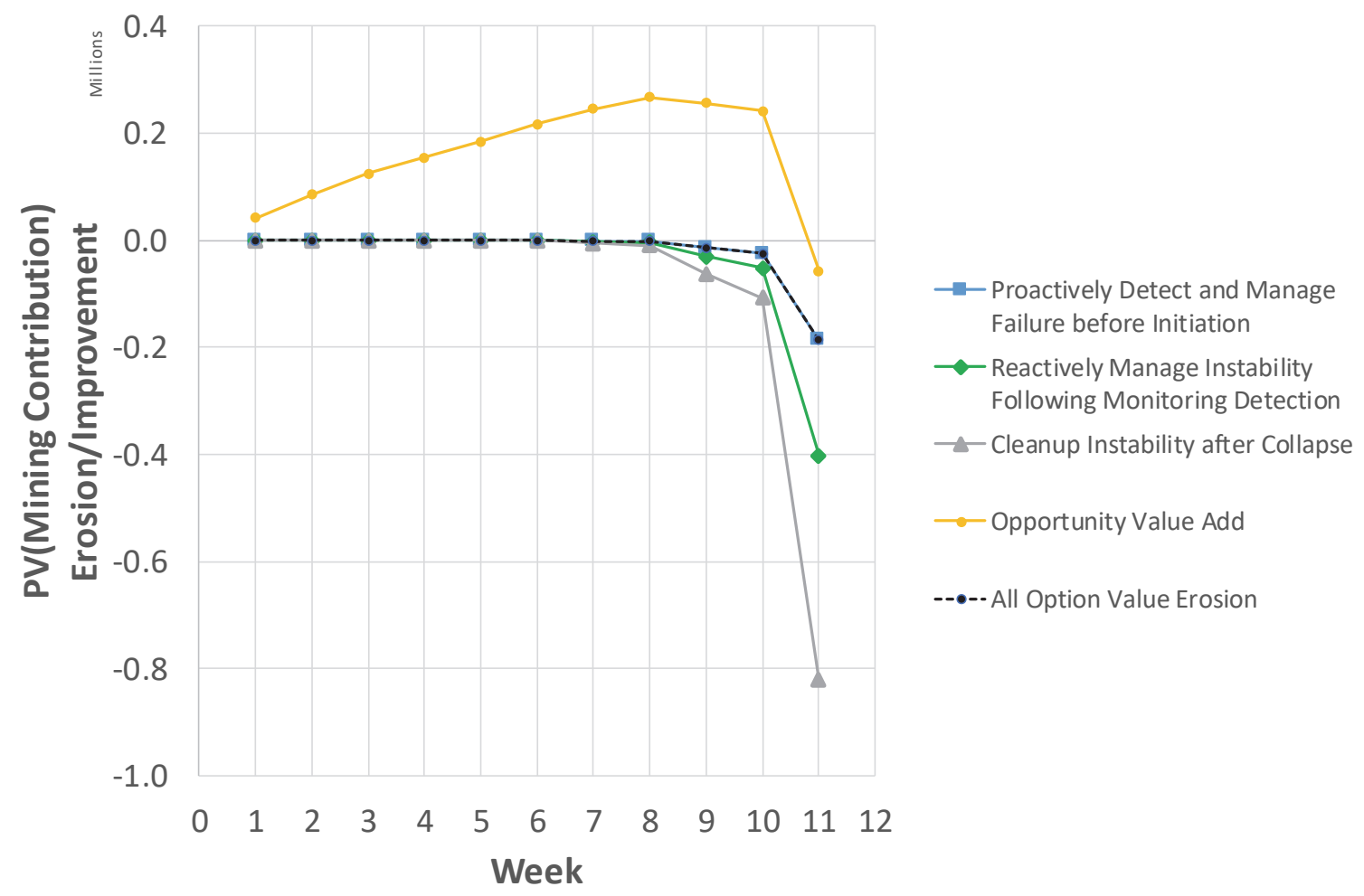

Figure $11 \mathrm{PV}$ (mining contribution) improvement/erosion

\subsubsection{Mining contribution erosion/improvement (value of options 1 and 2)}

The same data presented in Figure 10 is presented as Figure 11. However, the data was normalised against the base case expected mining contribution to make changes easier to see. Figure 12 shows that the value erosion of allowing slope instability to occur without preventative action is USD 820,000 while the value erosion of option 2 is only USD 403000 . The value of purchasing option 2 is therefore USD 417,000 (USD 820,000 - USD 403,000 = USD 417,000) as it represents the difference between the default value erosion of USD 820,000 and the option 2 value erosion (i.e. a benefit of USD 417,000 is achieved which represents the maximum price one could pay).

Similarly, the value erosion of purchasing option 1 is USD 187,000 so the value of option 1 is USD 633,000. In practice this means it would have been worth spending up to USD 417,000 on monitoring over the 11 week period to buy early knowledge of impending slope instability. Similarly, it would have been worth spending up to USD 633,000 on only option 1 . As the combined options value in this case is also USD 633,000 it would have been worth spending USD 633,000 on purchasing options 1 and 2 (i.e. proactive and reactive geotechnical risk-management tools). For the example pit, however, as stated earlier the short pit duration and shallow saprolitic failure mechanisms, technically prevented option 1 from being available so only option 2 remained. 


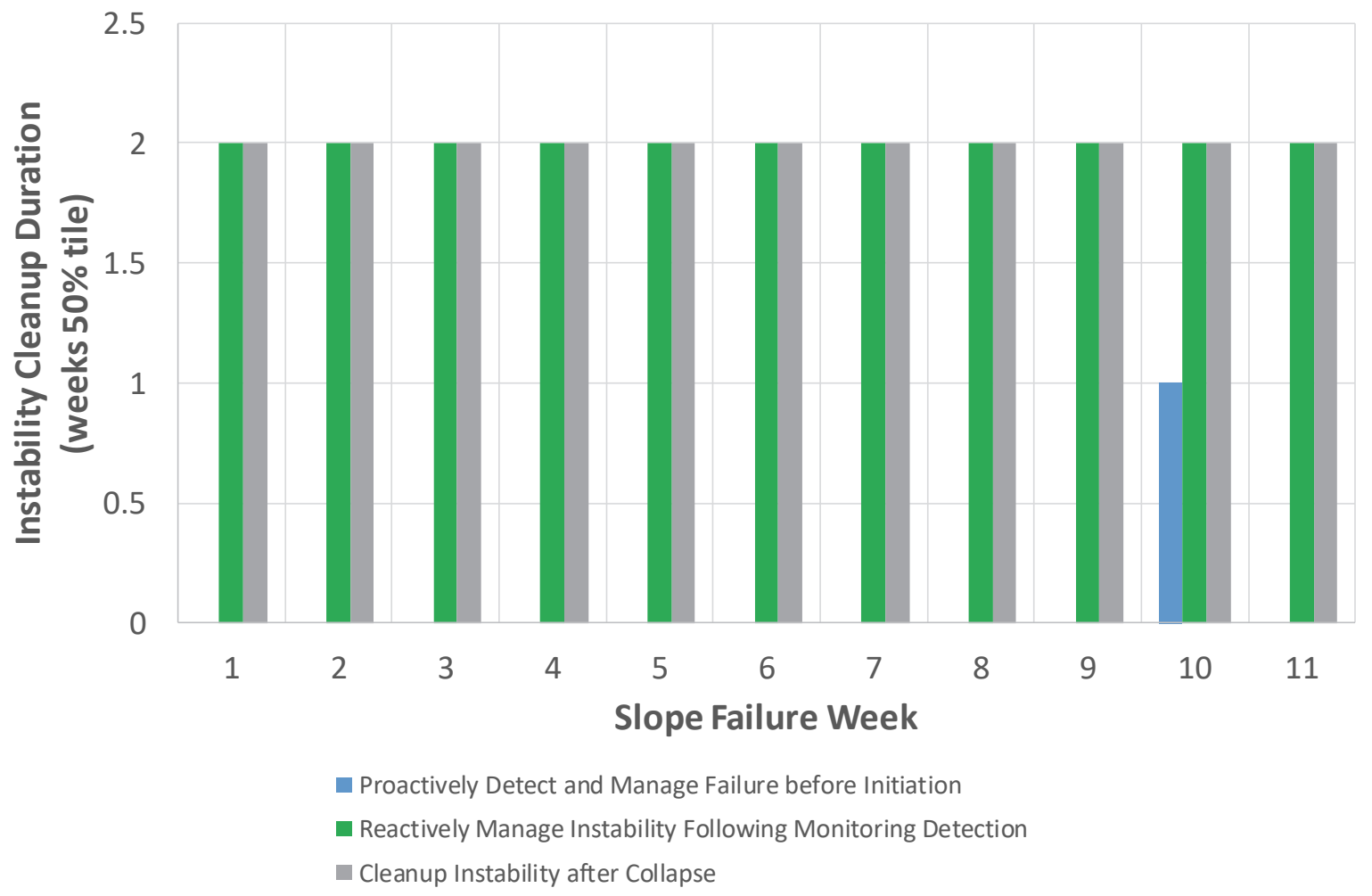

Figure 12 Net present value improvement/erosion

In addition, steepening the slope from $39^{\circ}$ to $42^{\circ}$ would have added value only up to week 8 whereafter value would be again destroyed. For a $42^{\circ}$ slope, an additional value of USD 267,000 could have been created if mining was stopped after week 8 compared to mining at $39^{\circ}$ up to week 11 . This is, however, only a simple comparison based on the assumed USD 1,200/oz gold price and if this risk assessment was done before mining, this result could have been provided to the mine planners for a rigorous mine planning evaluation before deciding on final pit shells. A rigorous mine planning assessment would include a sensitivity on gold price assumptions.

\subsubsection{Slope instability clean-up duration}

Figure 12 shows the last output for this paper, which is the slope instability clean-up duration. In each case shown here the slope instability clean-up duration is presented, although in reality the model produces a distribution that can be analysed further. This is an important measure, not only in that it allows the determination of stockpile size, but it also demonstrates the differences between purchasing options 1 and 2, versus cleaning up a slope instability. For option 1: proactive risk management, the assumption is made in the model that the mine will only proceed with proactive measures as long as it can be done without causing a normal production delay (i.e. causing a gap in production output). For this reason, the production gap is zero and instability clean-up duration is only provided in so far as it disrupts production based on the resources declared in the risk model.

For the reactive measures the mine no longer has a choice; the slope instability needs to be dealt with, so some optionality is lost. Choosing to remediate a slope therefore may occur at the cost of production and this gap is calculated based on the volume of material to be moved and the mining rate. From Figure 12 it can be seen that option 1 would only have resulted in a production delay in week 10. Option 2 would have resulted in a remediation duration of about two weeks. Lastly, allowing a slope to fail will also result in a two week clean-up time. Production delays would, therefore, have been the same for both option 2 and allowing slope instability to occur. Option 1 would have provided the only benefit, but was technically not feasible. 


\section{Discussion}

The results presented in this paper demonstrate that the value of geotechnical risk management can be quantified in terms of option 1: proactive risk management, and option 2: reactive risk management, compared to allowing option 3: slope instability and managing the aftermath. Both options can be valued in dollar terms, and used to make decisions about the amount, type and timing of geotechnical effort for an open pit.

Finally, the results also showed that for the example open pit, which is a small saprolite pit, option 1 was not available, but would have been the most valuable if it was practical. Option 2 would have been the second most valuable, but at the time it was needed when slope instability started to occur in week 11 , it was too late to respond and no additional value would have been added if it was implemented.

In reality, the actual pit was mined to week 10 before instability in week 11 sterilised the remaining ore. The instability was driven by groundwater which had intersected the pit in week 10, whereas weeks 1 to 9 were dry. Such a result is also expected given the Probability of Failure versus depth graph presented in Figure 9. In reality therefore, the mining contribution realised is shown by the orange line in Figure 11 up to week 10 and then the grey line for week 11 which represents only a small value reduction. Similarly, the actual normalised value reduction is presented by the horizontal axis in Figure 12 up to week 10 and the grey line for week 11 representing value destruction of approximately USD 700,000 (value from Figure 10). The decision to only monitor and not carry out a pit-specific site investigation program was a reasonably good one considering the cost of drilling, sampling and testing samples for the pit which may well have been in a similar range, especially if mining delays and opportunity costs are considered. There is, however, now an argument to be made for selecting the value add opportunity slope angle for the next pit in similar saprolites provided the pit is stopped short of the water table.

\section{Conclusion}

Using the model presented by Venter and Hamman (2018b), it is now possible to quantify the value of geotechnical activities for open pits based on the concept of real options. For the example pit, purchasing option 1 appears the most valuable; however, the cost of purchasing option 1 (i.e. drilling sampling, lab testing, design and schedule delays) would have outweighed the value add. Consequently, option 2, which was carried out, then became the next most valuable option. However, given the quick initiation at the last bench, it was not practical. The final result is that the default position: managing the instability, remained.

This paper showed the application of the Venter and Hamman (2018b) economic risk model to a small saprolite pit. It would be interesting to see how the model would fare when applied to larger pits with complex failure mechanisms.

\section{Acknowledgement}

The authors thank the technical teams in West Africa and the management of AngloGold Ashanti for the opportunity to present this paper.

\section{References}

Contreras, L \& Tunono, A 2011, 'Probabilistic stability analysis for pit slope optimisation at Jwaneng Mine, Botswana', Civil Engineering, April 2011, pp. 53-56.

Contreras, L \& Steffen, OKH 2012, 'An economic risk-based methodology for pit slope design', Australian Centre for Geomechanics Newsletter, December 2012, pp. 7-13.

Contreras, LF 2015, 'An economic risk evaluation approach for pit slope optimisation', Journal of the Southern African Institute of Mining and Metallurgy, vol. 115, no. 7, pp. 607-622.

Contreras, LF, Lesueur, R \& Maran, J 2006, 'A case study of risk evaluation at Cerrejon Mine', Proceedings of the International Symposium on Stability of Rock Slopes in Open Pit Mining and Civil Engineering Situations, South African Institute of Mining and Metallurgy, Johannesburg.

Crundwell, FK 2008, Finance for Engineers: Evaluating and Funding Capital Projects, Springer-Verlag, London. 
Hull, JC 2003, Options, Futures, and Other Derivatives, 5th edn, Prentice Hall, New Jersey.

Steffen, OKH, Contreras, LF, Terbrugge, PJ \& Venter, J 2008, 'A risk evaluation approach for pit slope design', Proceedings of the 42nd US Rock Mechanics Symposium, American Rock Mechanics Association, Alexandria.

Terbrugge, PJ, Wesseloo, J, Venter, J \& Steffen, OKH 2006, 'A risk consequence approach to open pit slope design', The Journal of the South African Institute of Mining and Metallurgy, vol. 106, pp. 503-511.

Venter, J \& Hamman, ECF 2019, 'A practical safety risk model for monitoring program design', Proceedings of the First International Conference on Mining Geomechanical Risk, Australian Centre for Geomechanics, Perth, pp. 195-204.

Venter, J \& Hamman, ECF 2018a, 'A temporal safety risk model for open pit slope management', Proceedings of Slope Stability 2018, Asociacion Nacional de Ingenieros de Minas and Colegio Oficial de Ingenieros de Minas del Sur, Seville.

Venter, J \& Hamman, ECF 2018b, 'Determining the optimum slope angle using an integrated mine planning approach', Proceedings of Slope Stability 2018, Asociacion Nacional de Ingenieros de Minas and Colegio Oficial de Ingenieros de Minas del Sur, Seville.

Wesseloo, J \& Read, J 2009, 'Acceptance criteria', in J Read \& P Stacey, Guidelines for Open Pit Slope Design, CSIRO Publishing, Collingwood, pp. 221-236. 
